\title{
Dealing with the Competition of English-language Export Editions: Voices from the Dutch Trade Book Market
}

\author{
Giulia Trentacosti ${ }^{1}$ D $\cdot$ Nick Pilcher $^{2}$ D
}

Accepted: 2 March 2021 / Published online: 21 March 2021

(C) The Author(s) 2021

\begin{abstract}
This project explores the responses of the Dutch trade book market to the everincreasing influx of Anglophone publications. Based on in-depth interviews $(n=42)$ carried out between 2015 and 2017 with Dutch publishing professionals, this research identifies the approaches and strategies they adopt to defend their market from the competition of English-language editions. Findings show that the main defence strategy used is to release translations simultaneously with Englishlanguage originals, but that this creates significant pressures on both publishers and translators. Concomitantly, there has been an increasing focus on Dutch originals and non-Anglophone books. The strategies and approaches documented in this study may be of interest for scholars and practitioners in relation to other book markets and linguistic areas facing similar circumstances.
\end{abstract}

Keywords Anglophone $\cdot$ Dutch $\cdot$ Publishing $\cdot$ Translation

\section{Introduction}

English language proficiency is growing globally with approximately 400 million people worldwide now speaking English to some degree [14]. In Europe, the most recent survey (Eurobarometer 386) showed that $38 \%$ of Europeans speak English, with close to $90 \%$ of the populations of some countries doing so, including the Netherlands, Sweden and Denmark [21]. Concomitantly, almost $100 \%$ of European pupils now learn English at school [22]. Likewise, at a higher education level, English Medium Instruction is growing rapidly in both Europe and the world [18], particularly due to the need for Higher Education institutions to attract teachers, researchers and students from anywhere in the world in order to increase their

Giulia Trentacosti

g.trentacosti@ rug.nl

1 University of Groningen Library, University of Groningen, Groningen, Netherlands

2 The Business School, Edinburgh Napier University, Edinburgh, UK 
international outlook and competitiveness [30]. This increase looks set to continue in Europe, despite the occurrence of political events such as Brexit. English is therefore deeply embedded within European societies in many domains, from business, to education, science, technology, travel, traditional and new media, as well as entertainment [51].

\section{Implications for the Publishing Industry}

The high level of English proficiency in Europe means that there are large numbers of bilingual and biliterate consumers who are already able to access English-language cultural products (TV series, films, magazines or books) without the need for linguistic mediation [e.g. 2,9].

Whilst this trend represents huge opportunities for Anglophone publishers, at the same time it has potentially serious adverse implications for publishers of works in other languages. In addition, technological developments in publishing, such as digitization and internet retailing, play a key role in developing a readership for Englishlanguage books in Europe by making English-language products easily and cheaply available to consumers [38, 43, 52, 53].

In the field of publishing studies, various scholarly and industry sources observe a growing readership for English-language texts in non-Anglophone European countries $[11,12,35,36,38-40,43,52]$. Yet, to date, most studies have not addressed this issue empirically, and there remains a paucity of detailed evidence to support these claims. In addition, with the exception of Craighill's analysis of the Swedish book market [11, 12], no studies have addressed the impact of the increasing competition of English-language texts on the various local-language publishing markets in continental Europe.

The research presented here aims to complement this existing literature by relating the perspectives of a number of publishing professionals working in the Dutch book trade who were interviewed $(n=42)$ in relation to their responses and adaptations to this changing landscape. The Netherlands represents an ideal location to study this particular phenomenon given the high penetration of English in Dutch society, demonstrated by the fact that surveys measuring English as L2 skills, such as the EF English Proficiency Index, regularly rank the Netherlands as one of the most proficient countries in the world [19]. English is widely employed in the Netherlands for intranational functions, e.g. in advertising, media, entertainment, business communication and, especially, higher education [1, 29]. Remarkably, around $17 \%$ of primary schools offer Dutch and English bilingual education [22]. At the higher education level, there are more than 1,000 English-taught university programmes and $90 \%$ of Dutch postgraduate degrees are offered in English [29, 57]. Indeed, the pervasiveness of English in the Netherlands is so deep as often to be considered a virtual second language [20]. To further exacerbate the issue, the book market in the Netherlands remains highly dependent on translations, with most translations originating from Anglophone countries [32]. Given the predominance of English and the reliance on Anglophone translations, the competition from English-language books can be expected to have severe repercussions in the Dutch 
market and is therefore an element that Dutch publishers need to take into account and address in their publication strategies.

Although this project relates the experience of the Dutch book trade in particular, and is thus limited to presenting the results from one country and one specific subfield of its publishing market (trade), the growth of English-language proficiency is a widespread phenomenon; thus the findings can be of relevance elsewhere [cf. 24]. In other words, it is anticipated that practitioners facing similar situations elsewhere in the world can compare their own experiences with those of the Dutch book trade, and draw on them to inform how they approach the increase in Anglophone products entering their markets.

\section{Publishing and Power Dynamics}

Undoubtedly, power and hierarchies play a key role in the publishing industry and this is found in abundant evidence in the voices of Dutch interviewees. Drawing on Bourdieu's field theory in relation to cultural production and the protocols for how agents interact with each other [5, 6], Thompson $[54,55]$ has illustrated the importance of power and relationships in publishing. In each sub-field of publishing (e.g. trade publishing, scholarly publishing) there are many actors, dynamics, and perceptions of value in relation to the different forms of capital at play. Agents operating in the field of publishing are greatly influenced by the capital and resources they have at their disposal [6]. This is especially important when comparing the acts and decisions of those operating in a small field with relatively little capital and resources, such as the Dutch trade market, to those of organizations with vast resources operating on a global scale, such as American and British companies.

As noted by Rivière, "depending on the language in which they are written books are not exchanged and distributed evenly across the globe" [45]. The crossnational circulation of books - either by way of translations or in the original language - is linked to the power relations between languages [32]. The rise of English as the chief language of globalization has determined the progressive domination of Anglophone publishing firms in the global marketplace [48-50]. The sociological approach to the study of translations showed that translation flows are highly unequal exchanges that favour dominant languages and determine a widespread lack of literary diversity in the international publishing field [31-33, 49, 50]. Given its 'hypercentral' position in the 'world system of languages' [16], English is today the most translated language across the world, accounting for more than half of literary translations worldwide [32].

The domination of English in the publishing field is not limited only to translations, given that a large number of second-language speakers of English worldwide are sufficiently fluent to access Anglophone texts without the need for translations. Thus, English-language publishers find themselves in an extremely favourable position, as they can rely on a huge extended linguistic area where English is spoken as a second language [23, 54]. This has allowed Anglo-American publishers to branch out their activities and export their products globally. Conversely, nations 
whose languages are not as widely spoken find themselves operating in much more restricted linguistic fields and are forced to concentrate their operations within their domestic borders.

The UK and US are the largest producers of books on the world, and, taken together, they produced in excess of 510,000 new titles in 2015 [34]. A key problem for Dutch publishers in this context is how to compete with such large Anglo-American companies with their base of 23 million Dutch speakers (including speakers in the Flanders and the Dutch Caribbean).

This problem is particularly acute given the fact that translations, and in particular translations from English, account for a large share of book production in the Netherlands. As estimated by Heilbron, translations accounted for $30 \%$ of the national book production in 2000, with the share of translations in the prose category amounting to $70 \%$ [32]. In a small market such as the Dutch one, the issue of competition from English-language editions becomes particularly pressing, given that Dutch publishers rely heavily on the profits from English translations. Nevertheless, this is by no means a new phenomenon, as Dutch publishers have a long history of competing with imported Anglophone editions. As noted by van der Weel [56], English-language books were already popular in the Netherlands starting from the nineteenth century — so much so that the Dutch book market represented the most profitable export destination for British publishers at that time. This has arguably been a factor standing Dutch publishers in good stead to deal with the current situation.

\section{Online Retailers, Digitization and Retail Price Maintenance}

As noted above, the huge recent increase in online retailers and digitization have been additional challenges the Dutch book trade has had to face. Such developments have made English-language contents more visible, and more easily and cheaply accessible [45]. Whereas, in the past, customers who wanted to buy English-language editions had to rely on the commonly limited English-language sections in physical bookstores, today Amazon and other online retailers offer a huge selection of titles and have a virtually unlimited shelf space. As a result, English-language titles are easily located through the internet and quickly delivered to home addresses $[38,53]$. Digitization has also allowed for the expansion of English-language reading in non-Anglophone markets, with e-books affording publishers the opportunity to reduce the costs and obstacles associated with physical distribution [52]. Although precise data on the growth of e-book exports are hard to come by, anecdotally the evidence points to significant increases [37].

In addition to online retailing and digitization, Retail Price Maintenance (RPM) systems play a key role in the dynamics of book export markets. RPM systems are widely employed across Europe, and the large majority of European countries (including the Netherlands) apply different variations of this model. Under an RPM system, it is the publisher's responsibility to set the retail price for consumers, and retailers are not allowed to sell books at a discounted price. However, RPM cannot be applied in the face of European competition legislation, meaning that imported 
editions of UK and US titles can be discounted without limits in European countries, whereas local-language editions are subject to RPM regulations [42]. Indeed, and as shown below, the exemption of foreign-language titles from RPM regimes can result in price discrepancies between local titles and imported ones which gives a competitive advantage to English-language editions vis-à-vis Dutch-language ones.

Before the voices of key individuals in the Dutch book trade are presented, this article first details how these voices were gathered and how the data were collected and analysed.

\section{Methodology}

The Netherlands was chosen as an ideal location in which to investigate how nonAnglophone trade book publishers were dealing with the influx of Anglophone publications due both to its high average level of English proficiency [19] and to the fact that English-language books are popular amongst Dutch readers [41]. According to the Dutch publishing association (KVB) foreign-language books accounted for as much as $15 \%$ of the total Dutch trade turnover in 2018 [41].

In terms of questions asked to the participants interviewed, these focused on areas such as the role and extent of Anglophone publications in the Netherlands and what possible strategies were being adopted to protect Dutch language publishing for the future. The approach to the data collection was a qualitative one, as the goal was to explore approaches and delve deeper into the interpretations [17] of the agents interviewed [13]. In-depth interviews were chosen because they allow for the further exploration of views when questions arise. Expert interviewees [24] were the specific target of the initial sampling. This initial sampling was purposive [15] and was used to first identify experts, who were then asked to suggest others they knew, in a snowball-type sampling approach within their specific professional network [cf. 55]. Interviewees consisted of acquisition editors at Dutch publishing houses with a significant number of translations to English in their lists; literary agents selling English-language rights to Dutch publishing companies; booksellers (in particular buyers for English language books); and English to Dutch translators. In total, 42 interviews were conducted over a period from September 2015 to April 2017. Interviews were conducted ideally face to face $(n=25)$ but also via Skype $(n=7)$, phone $(n=5)$ and email $(n=5)$ where this was more suitable for the interviewees. On average interviews lasted 33 min. All interviews were conducted with informed consent, anonymously, and transcripts were sent back to interviewees for verification before any data were used [cf. 44]. Interviews were conducted in English, which was a second language to both interviewer and interviewee, but the proficiency levels of both were sufficient to ensure that the language of the interview did not constitute a barrier [10]. The interviews were transcribed by one of the researchers alone $[5 ; 46]$. These transcripts were then analysed using an approach similar to that of a thematic analysis [7] whereby themes were already predetermined and top down, but at the same time space was made for themes to emerge from the bottom up. The results of this analysis are now presented and discussed below. 


\section{Findings}

The next section presents, analyses and discusses the findings from the interviews in three broad sections. The first considers the perceptions of those in the Dutch book trade regarding the extent of the influx of Anglophone editions and how this competition influences the rights acquisition practices of Dutch publishers. The second section relates interviewees' perspectives on simultaneous publication, which was found to be the key defence mechanism adopted by Dutch publishers against the competition deluge from Anglophone editions. Thirdly, there is a section that outlines Dutch publishers' increased focus on local and non-Anglophone authors.

\section{The Extent of the Influx and Influence on Rights Acquisition Decisions}

When asked about the role of English-language editions in the Netherlands, interviewees were quite varied in their views with regard to whether-and up to what point-English-language editions represented a source of concern to them. Some interviewees considered there was little threat at all, given that few readers consumed English-language editions, one acquisition editor noting that 'I think there will always be a group of people reading in English, but it's such a small group'. For this editor it was better to focus on the Dutch reading market rather than 'worrying about what happens if they read in English: I don't worry too much about it.' For editors sharing these views Anglophone editions were similarly not considered a significant threat, except perhaps, as one of them said, for 'certain books that people prefer to read in English.'

Yet, not all editors were of the same opinion, and some felt Anglophone editions constituted a considerable threat, particularly for specific types of books and with certain specific sectors and (sub)genres. Interviews showed that editors routinely assessed (on a title-by-title basis) the level of risk posed by English-language originals when considering Anglophone manuscripts for acquisition. In cases where the risk was regarded as too high (i.e. if the competition could impinge on the commercial viability of the publication), editors could decide to reject manuscripts. Thus, the fear of competition from English-language editions was found to be an additional element that Dutch publishers factored in when evaluating the commercial viability of a manuscript. One editor related how there were some books they just did not translate as they felt the competition would be too great, saying 'For instance, a book about pop-music... you know that people that enjoy American music will be able to read the book in English and will buy the English edition.'

The factors that interviewees relied on to determine whether a title would be at risk of suffering from the competition of English-language originals included: the age of the target group, the level of anticipation for the release and the level of popularity of an author, the book's genre or sub-genre, the subject matter, the style of the writing, and whether a title belonged to the up-market or commercial spectrum. The following categories of books were regarded as most at risk:

- Books aimed at a young target audience (e.g. YA literature); 
- Books belonging to the up-market spectrum, with a highly educated target audience;

- Niche sub-genres such as fantasy, sci-fi, and business books;

- 'Big books' around which there is 'buzz' [cf. 55], or anticipated books by established authors;

- Books with specific stylistic features (e.g. the unique voice of the author) for which the mediation of a translator could be perceived by readers as diminishing the authenticity of the reading experience (e.g. books by comedians, autobiographies, etc.).

As one Young Adult (YA) literature editor noted, the competition in this sector is much greater, 'because younger generations are more used to encompassing English in their Dutch lives.' This editor felt readers would be much more likely to pick up a YA book 'in English, because it's cheaper, or available quicker, but also because it's considered higher status if you read in English.' Here clearly, the value of reading in English came to the fore, along with the issue of the lower price point of Englishlanguage editions.

Another theme that emerged was that interviewees, perhaps in line with the division of perspectives above on the scale of the threat from Anglophone editions, was that rarely were data consulted about how many English language editions were sold. In the words of one editor, 'Usually it is more of a gut feeling, things you notice when you walk in a bookshop and you see a big stack of the imported edition of a book you also published and you think that this is not good news for your edition.' Others felt that the published data were incomplete, saying for example that 'Because we don't know... how truthful it is, I prefer not to look at it. Since a lot of sales are made through Amazon you just don't know.'

Indeed, where statistics to consult were commented on, it was often to observe how there was a dearth of them, or to say how they were unreliable, and that instead it was gut feeling that was the preferred decider. Notably, and understandably, the importance of having experience and know-how was emphasized here, as one editor observed, "Things are generally learned "the hard way", through experience and through trial-and-error.' Often, as described above, this could be through either an assessment of the young age of the target audience or a judgement "on how "big" the author is or-in the case of a debut-how big we think they will become.' For example as one editor commented, 'When the new Harry Potter came out in English, everyone flocked to the stores.'

The way interviewees described their assessments and their decision-making process supports Bourdieu's notion of 'feel for game'-i.e. an internalized knowledge of the logics of the field that social actors develop by participation in the field [cf. $6,55]$.

\section{Simultaneous Publication}

In terms of the strategies for dealing with the competition from Anglophone editions, interviewees commented on both a number of approaches they adopted, and 
on the issues involved with them. The main approach to counter the competition from Anglophone publications was to publish before the English edition or simultaneously in the Dutch language. As one marketing specialist noted, 'they [Dutch publishers] always want to publish at the same time as the English edition which makes it hard since they have to translate quite quickly.' Many acquisition editors commented similarly that publication in Dutch would be aspired to as soon as possible, the reason, as one editor explained, being as follows: 'that you don't want to have the time gap in which people have heard of the book, want to read it, and then go for the American or British edition.' Notably, simultaneous publication was perceived to be more common in the Dutch market than in other European markets as the level of English proficiency here was so high. One literary agent that sold rights into various European markets defined this practice as a 'very significant feature of offering rights to Dutch publishers'. Dutch publishers stated that they strove to publish translations on the same day as-or as close as possible to-the release of the English language original whenever they thought that a book was likely to be read in English. Simultaneous publication was said to be common mostly with well-established best-selling authors, and with much anticipated books-i.e. the same categories mentioned above as being at risk of competition.

Also, in order to publish earlier than the original edition, occasionally Dutch publishers arranged special deals with authors that allowed them to release the Dutch translation ahead of the original work, 'for instance, the new Donna Tartt was published in Dutch before the English edition.' Although such practice is not the norm and happens relatively rarely, it is a key approach illustrating Dutch publishers' efforts to compete with English original publications. Nevertheless, there were also potential pitfalls with early translation; for example, the English version may have different covers, or internal artwork, or, as one editor noted, 'sometimes they [the original Anglophone publishers] have wonderful marketing ideas' and 'if you're very early [with your translation] you miss a little bit of information.'

Dutch companies were particularly keen on synchronizing the release if they expected a substantial amount of publicity for the title coming from the Anglophone media. This is because this meant that the Dutch edition could benefit from the attention generated by the original edition, as one editor noted metaphorically: 'If something is in the New York Times, it's more likely to get picked up by Dutch newspapers... it's very handy to move on the same train.'

Concerning publicity and PR, various interviewees expressed concern about the fact that the Dutch press occasionally reviewed original-language editions before Dutch translations were released. In addition, when the English language edition of the book was reviewed, even if a Dutch version was due to be released soon or was already published, the reviewers sometimes failed to mention this. As one editor noted, 'they review a book and they avoid to mention that there is also a Dutch edition available, which is quite annoying.' Some interviewees showed a more relaxed attitude towards this problem, noting that, since the importance of book reviews in newspapers had declined, the timing of reviews was not necessarily a problem. In fact, they explained that it could sometimes even be advantageous to have Dutch reviews ahead of the release of the translation, as they could be used to promote the 
book, as one editor explained: 'I used to think that was very annoying, but now I think it gives you a good quotation before your edition is published'.

Nevertheless, while releasing translations simultaneously to originals was considered key for anticipated titles by well-known authors, the exact opposite was generally true for works that were not expected to become immediate best-sellers, such as titles by debut authors who did not have an established readership. Many interviewees indicated that in these cases the general practice was that of scheduling the release of the Dutch edition after the original one, in the hope that the book would gather international media attention, as noted by one editor: 'you usually want to publish a debut after the original because you want the press coverage.' Another interviewee echoed: 'when you know a book is going to sell you want to be right on time, but if you don't know because it's a debut, sometimes the English edition can have a very positive effect on the sales of your own edition.' Thus, the presence of English editions was not always perceived as a purely disruptive factor for Dutch publishers. On the contrary, the success of the English edition could well be a beneficial phenomenon that the Dutch language edition is able to harness and 'piggy-back' onto to become more successful itself. This clearly highlights the high level of complexity of the phenomenon under investigation. The transnational and globalized nature of book circulation can represent both a threat to local publishers (due to the competition of English-language editions in their domestic market) but also an opportunity (thanks to the international hype from the original territories that assists the promotion of translated editions).

Simultaneous publication involves a series of practical challenges. Firstly, in order to synchronize the publication date with the original, Dutch publishers have to acquire translation rights early on so that they can ensure sufficient time to have the book translated. As one publisher commented, "when you look at catalogues of foreign publishers, Dutch publishers are most of the times among the first ones to buy the foreign rights.' Many Dutch acquisition editors felt that, if the rights to an Anglophone title were offered to them late-which meant that simultaneous publication was not achievable-this would influence their decision regarding whether to buy or not the rights. As one editor explained: 'I am really hesitant to buy anything that is already in the market, or which I know I cannot publish simultaneously, because I know that I am already behind'.

Another complication was that Anglo-American publishers only shared manuscripts quite late, 'only about a month or two before the publishing date' and this meant that "we still need to translate it and edit it, which will take us at least 3-4 months, so we are always late unless we get the manuscript earlier on in the process.' Receiving manuscripts early on was considered essential in order to organize simultaneous releases. Various interviewees stated that, as soon as they acquired the foreign rights to a book, they asked the original publisher (or rights holder) to share the manuscript so that they could start the translation; even, notably, when the manuscript was not final. Therefore, Dutch translations were often based on non-final manuscripts, which in turn was said to complicate the translation process, since translators had to implement changes as soon as new versions of the manuscript were received. As one editor noted, 'this means more work and also means an increased risk that some errors [...] and small discrepancies might occur between 
your translation and the original final proofs. However, that is usually at the level of words, not at the level of the plot line, so it's usually not a big problem.'

Lastly, the need to publish simultaneously meant that occasionally more than one translator was employed to translate the same book if time was extremely short: 'Sometimes we get books in too late and it has to be translated in a month and you can't have one person translate 100,000 words. So then you get 4 people translating that.' On the one hand, by using multiple translators, the duration of the translation process could be reduced significantly; on the other hand, more editorial supervision was necessary to avoid stylistic inconsistencies. For this reason, various interviewees stated that they usually employed external proof-readers to check that the style of the translation was consistent throughout the book. Thus, interviews revealed that the practice of translating from non-final manuscripts and that of group translations not only had an impact on the publication strategies of Dutch publishers, but also on translators.

\section{Increased Focus on Domestic and Non-Anglophone Literature}

A number of interviewees highlighted the emergence of a new trend whereby Dutch publishers were publishing fewer translations from English and concentrating more on Dutch authors and authors in other languages. In the words of one editor: 'We are now looking into different markets. I am trying to find books from Italy and Spain, because nobody can read those languages'.

Two acquisition editors and a literary agent found that the interest for indigenous authors had increased compared to the past, whereas the interest for Anglo-American authors had declined. As one acquisition editor noted, 'I think there is a trend where you see that people are focusing on things closer to home than they used to do. There was a trend towards internationalization in the $1970 \mathrm{~s}-80 \mathrm{~s} . .$. then there was a lot of interest in international literature, more so than now. I think it's not the same as it was 30 years ago'. Similarly, another editor commented that, 'if you look at the bestsellers list now, as opposed to 10 years ago, you'll notice that a lot of the bestsellers now are Dutch, and a lot of them 10-15 years ago were the global bestsellers, like big thrillers originally in English [...] the best sold thrillers now in the Netherlands are those that take place here in Holland. Before it used to be New York, Chicago, but that doesn't happen anymore'. This was reflected in the words of a literary agent, who commented that 'I have been selling rights to the Netherlands since about the year 2000 and I would say that over the last 16 years [...] publishers are acquiring fewer English-language authors' rights than they used to do. And it's also true to say that they're publishing more Dutch authors than they used to'. Notably, according to one interviewee these trends were part of an initiative to promote local authors: 'We try to publish more homegrown talent.' Rather than being seen as specific to the Dutch book trade, this trend was seen as a more widespread phenomenon. According to one literary agent, the growing interest for local cultural products not only affected the market for Anglo-American translations, but also meant a widespread decline in translations from other languages. This interviewee felt that, despite the occasional peak of popularity for books from certain languages 
(e.g. Scandinavian crime), on the whole European publishers' lists were less diverse, due to the fact that companies operated in increasingly challenging economic circumstances. One Dutch acquisition editor echoed this view by highlighting a specific link between the decline that affected the Dutch book market in the aftermath of the 2008 economic crisis [26] and the decrease of translations in favour of Dutch authors. Furthermore, various interviewees agreed that one of the main drivers behind this shift towards Dutch authors was the fact that they were easier to market since they spoke Dutch and were available to do promotional activities locally (e.g. TV shows, blogging, etc.), as one editor pointed out: 'It is simply easier to market and sell books from Dutch authors, because they are available for interviews. Since they are in the same cultural context, it's easier to get their message across'.

In addition, many interviewees noted that another key driver behind this trend was the fact that the publishing of Dutch-language books was much cheaper than publishing translations: 'Translation is expensive, you have to buy the rights, you have to be prepared to pay the author an advance and then find a translator and pay him or her. Before you even get a translated book out on sale, you're in for probably $£ 10,000$ of expenditure'. One interviewee added that cost considerations were particularly pertinent to translations from English, since there were usually no subsidies in place to support translations from English, whereas other languages frequently have translation subsidies that help foreign publishers cover the translation costs.

Overall, these data suggest that, although the competition of English-language editions reduces publishers' ability to profit from translations, this should not be regarded as the only driver behind the growth of local-language content in the Netherlands. In fact, the shift towards local content was mostly linked by interviewees to the fact that Dutch authors were considered easier to market, and to the fact that the publishing of Dutch originals was cheaper given no translation costs were involved.

\section{Discussion and Conclusions}

The huge global expansion in English speakers and language usage arguably poses a number of challenges and potential threats to a country's native language publishing trades. However, very few studies to date have focused on this phenomenon. This project conveyed voices from the Dutch book trade regarding how publishing companies are dealing with the circulation of Anglophone editions.

Dutch editors showcased different perspectives on the role of English-language editions in their market. While some were highly concerned by the competition of English originals (e.g. YA publishers), others downplayed the phenomenon, stating that the competition represented a problem only for 'certain books'. Although acquisition editors appeared confident about their ability to judge which manuscripts were at risk of being predated by the English editions, they were elusive when it came to specifying their evaluation criteria [cf. 30]. Notably, most interviewed acquisition editors said they did not monitor sales of English-language editions systematically, stating that their judgement on this issue was mostly based on intuition and 'gut feeling'. The way interviewees described their decision-making process resonates strongly with Bourdieu's notion of 'feel for game' $[6,55]$. 
There were a range of factors that interviewees took into account when evaluating whether a title would be at risk of suffering from the competition of English-language originals. These included factors such as the age of the target group, the popularity of an author, the genre or subject of the book, and whether it belonged to the up-market or commercial spectrum of the market. If the competition was considered to impinge on the commercial viability of the publication, editors said they would decide to reject manuscripts on this basis. Thus, one key defence mechanism against the influx of English-language editions consisted of adapting rights acquisition practices by avoiding translations which were considered too risky. These data enhance our understanding of the decision making process of Dutch acquisition editors, and expands on and complements earlier studies on the subject which did not focus on the role of the competition of English-language editions [cf. 27,28].

Another way in which the fear of competition from English-language originals influenced rights acquisition practices was by leading Dutch publishers to buy the translation rights of Anglo-American books early on, so as to allow synchronized publication with original English-language editions. In a previous study analyzing the decision-making processes of Dutch acquisition editors, Franssen and Kuipers described Dutch editors as being in a constant 'hurry' when acquiring AngloAmerican translation rights (significantly more so than with manuscripts in other languages), due to the size and the speed of the Anglo-American market [27]. When buying English-language manuscripts, Dutch editors were found to rarely wait to see how well a book sold in the original territory; instead, they often bought AngloAmerican translation rights early on (ibid). The data presented here confirm Franssen and Kuiper's conclusions and expand on them by showing that, not only was it the case that Dutch editors bought English-language manuscripts faster due to the speed and abundance of publications in the Anglophone market, but also because they needed to publish Dutch translations simultaneously with original editions in order to avoid losing readers to English-language editions.

The most tangible way in which the competition of English-language editions was found to influence the publishing strategies of Dutch companies was by motivating them to publish simultaneously or in advance of the original publication, especially in cases of books considered at risk of being bought in English-although this was less so for debut authors. Synchronized publication was also considered a necessity for publicity and marketing reasons. According to the experts interviewed here, given the transnational nature of publishing markets, the hype surrounding popular titles in the Anglophone market reached Dutch consumers very quickly, and simultaneous publication allowed them to benefit from this phenomenon.

Publishing simultaneously was shown to have a significant impact on many aspects of the publication process, from rights acquisitions (i.e. editors sometimes declining manuscripts in case they could not publish simultaneously), to publishing and translation practices. In order to release translations simultaneously, Dutch publishers not only have to be quick in acquiring translation rights, but they also have to translate rapidly. To do so, they often demand translators to use partial or non-final manuscripts as source texts, as well as employing teams of translators to accelerate the process. 
Another key finding emerging from this study is that Dutch publishers are increasingly publishing more Dutch-language and non-Anglophone authors than in the past. The competition of English-language editions was mentioned as an additional driver in this shift towards local-language and non-Anglophone contents-however, this factor was not considered to be the decisive one. The trend was instead attributed to a variety of factors. Of these, one was the fact that Dutch-language and nonAnglophone titles were cheaper to publish due to the absence of translation costs for Dutch books and to the lower cost of non-Anglophone translation rights. Another was the fact that Dutch authors were considered easier to market, given their availability to take part in local promotional activities. In addition, Dutch editors made a connection between this trend and the 2008 economic crisis and its effects on the Dutch publishing market, which forced many companies to cut budgets and reorganize their operations [26]. While previous studies showed that translations from English dominate the market in most European countries, the qualitative data presented here suggests that Dutch publishers are instead consciously and deliberately translating less from English [cf. 32,33,47,49,50].

Ultimately, the data from this study shows that competition from Anglophone editions is shaping and influencing the rights acquisition decisions and publication practices of Dutch publishers profoundly, causing an acceleration of publication rhythms which is felt to exert significant pressure on both publishers and translators. Whilst the present article focuses on the Netherlands, it is hoped that the findings and strategies conveyed above can be considered in relation to other book markets and linguistic areas. It is also hoped that future avenues for study can be followed elsewhere, for example in attempting to identify quantitative data about the impact and nature of the trends described above. The issue of the impact of English Language editions is not a Netherlands-bound-(or Swedish-bound [12])—issue alone; rather, it is a global one, and more studies will help shed light upon how countries and publishers are reacting to it.

Open Access This article is licensed under a Creative Commons Attribution 4.0 International License, which permits use, sharing, adaptation, distribution and reproduction in any medium or format, as long as you give appropriate credit to the original author(s) and the source, provide a link to the Creative Commons licence, and indicate if changes were made. The images or other third party material in this article are included in the article's Creative Commons licence, unless indicated otherwise in a credit line to the material. If material is not included in the article's Creative Commons licence and your intended use is not permitted by statutory regulation or exceeds the permitted use, you will need to obtain permission directly from the copyright holder. To view a copy of this licence, visit http://creativecommons.org/licen ses/by/4.0/.

\section{References}

1. Berns MS, De Bot K, Hasebrink U. In the presence of english: media and European youth. New York: Springer; 2007.

2. Bernstein A, Sekine N, Weissman D. The global music industry: three perspectives. London: Routledge; 2013. 
3. Bird CM. How I stopped dreading and learned to love transcription. Qual Inq. 2005;11(2):226-48.

4. Bourdieu P. The rules of art. Stanford, CA: Stanford University Press; 1996.

5. Bourdieu P. A conservative revolution in publishing. Trans Stud. 2008;1(2):123-53.

6. Bourdieu P, Johnson R. The field of cultural production. New York: Columbia University Press; 1993.

7. Braun V, Clarke V. Using thematic analysis in psychology. Qual Res Psychol. 2006;3(2):77-101.

8. Campbell, L., Jones, P. US publishers' exports pick up the pace. The Bookseller. 2012 [online] Available at: https://www.thebookseller.com/news/us-publishers-exports-pick-pace.

9. Chalaby JK. Transnational television in Europe: reconfiguring global communications networks. New York: IB Taurus; 2009.

10. Cortazzi M, Pilcher N, Jin L. Language choices and "blind shadows": investigating interviews with Chinese participants. Qual Res. 2011;11(5):505-35.

11. Craighill, S. 'National literature is now rather an unmeaning term; the epoch of world literature is at hand'. Notions of Capital and Symbolic Power in the Globalised European Fiction Market. Ph.D. Edinburgh Napier University. 2013

12. Craighill S. The problem of english language export fiction in Europe. Publ Res Q. 2015;31(2):91-101.

13. Creswell JW, Poth CN. Qualitative inquiry and research design: choosing among five approaches. Thousand Oaks, Calif: SAGE Publications; 2018.

14. Crystal D. The language revolution. Hoboken: Wiley; 2018.

15. Daniel J. Sampling essentials: practical guidelines for making sampling choices. Thousand Oaks, Calif: Sage Publications; 2011.

16. De Swaan A. Words of the world. Cambridge, UK: Polity; 2001.

17. Denzin N, Lincoln Y. Introduction: the discipline and practice of qualitative research. In: Denzin N, Lincoln Y, editors. The SAGE handbook of qualitative research. Thousand Oaks, Calif: SAGE Publications; 2017. p. 1-26.

18. Doiz A, Lasagabaster D, Sierra JM. Internationalisation, multilingualism and English-medium instruction. World Englishes. 2011;30(3):345-59.

19. Education First. EF English Proficiency Index. 2020 [online] Available at: https://www.ef.com/ assetscdn/WIBIwq6RdJvcD9bc8RMd/legacy/_/ /media/centralefcom/epi/downloads/full-repor ts/v10/ef-epi-2020-english.pdf

20. Edwards A. English in the Netherlands: functions, forms and attitudes. Amsterdam: John Benjamins; 2016.

21. Commission E. Special Eurobarometer 386: Europeans and their languages. Brussel: European Commission; 2012.

22. Eurostat. $84 \%$ of primary school children study foreign languages. 2015 [online] Available at: https://ec.europa.eu/eurostat/web/products-Eurostat-news/-/EDN-20170925-1.

23. Feather J. Communicating knowledge: publishing in the 21st century. Berlin: De Gruyter; 2003.

24. Flick U. An introduction to qualitative research. Thousand Oaks, Calif: Sage Publications; 2014.

25. Flyvbjerg B. Five misunderstandings about case-study research. Qual Inq. 2006;12(2):219-45.

26. Franssen, T. Uitgeven in tijden van crisis. Vrij Nederland (12-4-2012). 2012 https://www.vn.nl/ uitgeven-in-tijden-van-crisis/.

27. Franssen T, Kuipers G. Coping with uncertainty, abundance and strife: decision-making processes of dutch acquisition editors in the global market for translations. Poetics. 2013;41(1):48-74.

28. Franssen, T. P. How books travel: Translation flows and practices of Dutch acquiring editors and New York literary scouts, 1980-2009. PhD Thesis: University of Amsterdam. 2015

29. Gerritsen M, van Meurs F, Planken B, Korzilius H. A reconsideration of the status of english in the Netherlands within the Kachruvian Three Circles model. World Englishes. 2016;35:457-74.

30. Graddol D. English next: why global English may mean the end of English as a foreign language. London: British Council; 2006.

31. Heilbron J. Translation as a cultural world system. Perspectives. 2000;8(1):9-26.

32. Heilbron J. Responding to globalization: the development of book translations in France and the Netherlands. In: Pym A, Shlesinger M, Simeoni D, editors. Beyond descriptive translation studies. Investigations in homage to Gideon Toury. Amsterdam: John Benjamins; 2008.

33. Heilbron J, Sapiro G. Outline for a sociology of translation. In: Wolf M, Fukari A, editors. Constructing a sociology of translation. Amsterdam: J. Benjamins; 2007. p. 93-107. 
34. IPA, International Publishing Association. Global Publishing and Reading Statistics. 2016 [online] Available at: https://www.internationalpublishers.org/images/annual-reports/2015_ online_statistics.pdf.

35. Jones, P. As the US e-book market develops, UK publishers may find some sales growth. The Bookseller. 2010 [online] Available at: https://www.thebookseller.com/futurebook/us-ebookmarket-develops-uk-publishers-may-find-some-sales-growth.

36. Jones, P. What does it mean that $96 \%$ of titles in the German Kindle store are in English? 2011a [online] Available at: https://www.thebookseller.com/futurebook/what-does-it-mean-96-titlesgerman-kindle-store-are-english.

37. Jones, P. English-language e-books in global surge. 2011b [online] Available at: https://www. thebookseller.com/news/english-language-e-books-global-surge [Accessed: 21 April 2019].

38. Kovač M. Global English and publishing trends at the turn of the 20th century. Knygotyra. 2014;62:7-17.

39. Kovač, M., Wischenbart, R. Diversity Report. Cultural diversity in translations of books: Mapping fiction authors across Europe. 2009a [online] Verein für kulturelle Transfers-CulturalTransfers.org. Available at: http://www.wischenbart.com/upload/Diversity_Report_2009.pdf.

40. Kovač M, Wischenbart R. End of the english (British?) empire? Or something else? Publishing Research Quarterly. 2009;25(2):118-27.

41. KVB. Kerncijfers boekenmarkt. 2019 [online] Available at: https://www.kvbboekwerk.nl/monit or/markt/kerncijfers-boekenmarkt-2012-2018.

42. Littoz-Monnet, A. "The Europeanisation of the Regulation of Book Markets: Fixed Price Systems for Books in the EU." In The European Union and Culture: Between Economic Regulation and European Cultural Policy, 101-19. Manchester University Press, 2007.

43. McCleery A. Maintaining the cultural exception: publishing literature in a global marketplace. In: Kelly WA, Trentacosti G, editors. The book in the low countries. Edinburgh: Merchiston Publishing; 2015.

44. Poland B. Transcription Quality. In: Gubrium JF, Holstein JA, editors. The SAGE Handbook of interview research. Thousand Oaks, Calif: Sage Publications; 2002. p. 629-49.

45. Rivière M. Plurilingual reading practices in a global context: circulation of books and linguistic inequalities. Stud Second Lang Learn Teach. 2017;7(2):335-54.

46. Robson C. Real world research: a resource for users of social research methods in Ahepplied settings. Chichester: John Wiley; 2011.

47. Sapiro G. Translation and the field of publishing. Transl Stud. 2008;1(2):154-66.

48. Sapiro G. Les contradictions de la globalisation éditoriale. Paris: Nouveau monde; 2009.

49. Sapiro G. Globalization and cultural diversity in the book market: the case of literary translations in the US and in France. Poetics. 2010;38(4):419-39.

50. Sapiro, G. Translation as a Weapon in the Struggle Against Cultural Hegemony in the Era of Globalization. Bibliodiversity Translation and Globalization: 31-40. 2014

51. Seidlhofer B, Breiteneder A, Pitzl M-L. English as a lingua franca in Europe: challenges for applied linguistics. Ann Rev Appl Linguist. 2006;26(1):3-34.

52. Shatzkin, M. As Europe's e-book market develops, US publishers may find some sales growth. [Blog] The Shatzkin Files. 2010. Available at: https://www.idealog.com/blog/as-europes-ebookmarket-develops-us-publishers-may-find-some-sales-growth/.

53. Steiner A. Across the internet: English book in Sweden in the 1990s. Publ Res Q. 2005;20(4):71-8.

54. Thompson JB. Books In the digital age. Cambridge: Polity Press; 2005.

55. Thompson JB. Merchants of culture. Cambridge: Polity Press; 2010.

56. Van der Weel AH. Dutch Nineteenth-century attitudes to international copyright. Publ Hist. 2009; 47:31-44.

57. Wächter B., Maiworm, F. English-Taught Programmes in European Higher Education. The State of Play in 2014. Bonn: Lemmens. 2014 [online] Available at: https://www.lemmens.de/dateien/ medien/buecher-ebooks/aca/2014_english_taught.pdf.

Publisher's Note Springer Nature remains neutral with regard to jurisdictional claims in published maps and institutional affiliations. 